\title{
Changes in Shoulder External Rotator Muscle Activity during Shoulder External Rotation in Various Arm Positions in the Sagittal Plane
}

\author{
Jun-Hyeor JAnG, PT, $\mathrm{PhD}^{1)}$, JAe-Seop Oh, PT, $\mathrm{PhD}^{2)^{*}}$ \\ 1) Department of Physical Therapy, Haeundae Jaseng Hospital of Oriental Medicine, Republic of \\ Korea \\ 2) Department of Physical Therapy, College of Biomedical Science and Engineering, Inje University: \\ 607 Obang-dong, Gimhae-si, Gyeongsangnam-do 621-749, Republic of Korea
}

\begin{abstract}
Purpose] The aim of this study was to investigate changes in electromyographic (EMG) activity of the infraspinatus and posterior deltoid muscles during shoulder external rotation under different shoulder flexion angles. [Subjects] Thirteen participants were included in this study. [Methods] The participants performed isometric shoulder external rotation at $45^{\circ}, 90^{\circ}$, and $135^{\circ}$ of shoulder flexion. A surface EMG system recorded the EMG activity of the infraspinatus and posterior deltoid muscles during shoulder external rotation. The changes in the muscle activity of infraspinatus and posterior deltoid and ratio of infraspinatus to posterior deltoid muscle activity were analyzed using one-way repeated-measures analysis of variance with Bonferroni's correction. [Results] The posterior deltoid activity was significantly decreased, while the ratio of the infraspinatus to posterior deltoid activity was significantly increased at $45^{\circ}$ of shoulder flexion compared with $90^{\circ}$ and $135^{\circ}$ of shoulder flexion $(\mathrm{p}<$ 0.05). There were no significant differences in the EMG activity of the infraspinatus among the three conditions ( $\mathrm{p}$ $>0.05$ ). [Conclusion] These findings indicate that shoulder external rotation at $45^{\circ}$ of shoulder flexion effectively reduced the contribution of the posterior deltoid activation to shoulder external rotation.

Key words: Infraspinatus, Posterior deltoid, Shoulder external rotation
\end{abstract}

(This article was submitted Jul. 17, 2013, and was accepted Aug. 17, 2013)

\section{INTRODUCTION}

In the human body, the shoulder joint is exposed to various potential injuries because it has a high degree of motion $^{1)}$. Most exercises designed to prevent and treat shoulder injuries have been established on the basis of strengthening the shoulder muscles, especially the rotator cuff (RC) mus$\operatorname{cles}^{2,3)}$. The RC muscles comprise the subscapularis, teres minor, supraspinatus, and infraspinatus muscles, which provide the shoulder joint with stability through compression of the humeral head into the glenohumeral fossa during dynamic motion ${ }^{4)}$.

During shoulder external rotation (ER), the infraspinatus muscle, one of the RC muscles, stabilizes the shoulder joint and acts as the prime mover ${ }^{2,5}$ ). Considering the roles of the infraspinatus muscle as the stabilizer and primary mover during shoulder ER, it is important to enhance selective activation of the infraspinatus muscle in RC strengthening and rehabilitation programs. Previous studies showed that shoulder ER in the side-lying and prone positions in-

*Corresponding author. Jae-Seop Oh (e-mail: ysrehab@inje. ac.kr)

(C)2014 The Society of Physical Therapy Science

This is an open-access article distributed under the terms of the Creative Commons Attribution Non-Commercial No Derivatives (by-ncnd) License $<$ http://creativecommons.org/licenses/by-nc-nd/3.0/>. creased the activity of the infraspinatus muscle; however, high electromyographic (EMG) activity of the posterior deltoid muscle was shown in these positions ${ }^{6}$. Because a high level of posterior deltoid muscle activation may induce translation of the humeral head during shoulder $\mathrm{ER}^{7,8)}$, how to reduce the contribution of the posterior deltoid muscle should be considered in the development of infraspinatus muscle strengthening exercises.

Some researchers have investigated exercises for selective strengthening of the infraspinatus muscle ${ }^{8,9)}$. Bitter et al. ${ }^{8)}$ suggested that shoulder ER with an adduction strategy under a low-load condition optimizes the contribution of the infraspinatus muscle. Ha et al. ${ }^{9)}$ reported that side-lying shoulder ER with the shoulder supported leads to greater activation of the infraspinatus muscle and less activation of the posterior deltoid muscle compared with prone shoulder ER and standing shoulder ER exercises. However, these exercises were performed at only $0^{\circ}$ of shoulder flexion ${ }^{8)}$ or various other positions ${ }^{9)}$; these positions likely do not reflect daily tasks involving shoulder ER under various arm positions in the sagittal plane ${ }^{10)}$. Furthermore, to develop an exercise protocol for selective activation of the infraspinatus muscle, how arm positions influence the EMG activity of the infraspinatus and posterior deltoid muscles must be determined. Therefore, the aim of this study was to examine the changes in the EMG activity of the infraspinatus and posterior deltoid muscles and the ratio of the infraspinatus 
Table 1. Infraspinatus and posterior deltoid muscle activity during shoulder external rotation in the three arm positions

\begin{tabular}{lccc}
\hline \multirow{2}{*}{ Muscle } & \multicolumn{3}{c}{ Mean \pm SD $(\%$ MVIC) } \\
\cline { 2 - 4 } & $45^{\circ}$ shoulder flexion & $90^{\circ}$ shoulder flexion & $135^{\circ}$ shoulder flexion \\
\hline Infraspinatus & $31.81 \pm 9.80$ & $35.10 \pm 14.40$ & $35.07 \pm 12.75$ \\
Posterior deltoid* & $2.73 \pm 1.33^{\dagger *}$ & $3.85 \pm 1.77$ & $3.97 \pm 1.70$ \\
\hline
\end{tabular}

${ }^{*} \mathrm{p}<0.05,{ }^{\dagger}$ Significant difference from $90^{\circ}$ shoulder flexion, ${ }^{\star}$ Significant difference from $135^{\circ}$ shoulder flexion

Table 2. Ratio of infraspinatus to posterior deltoid muscle activity during shoulder external rotation in the three arm positions

\begin{tabular}{cccc}
\hline \multirow{2}{*}{ Ratio } & \multicolumn{3}{c}{ Mean \pm SD $(\% \mathrm{MVIC})$} \\
\cline { 2 - 4 } & $45^{\circ}$ shoulder flexion & $90^{\circ}$ shoulder flexion & $135^{\circ}$ shoulder flexion \\
\hline Infraspinatus / posterior deltoid* & $13.92 \pm 6.40^{\dagger *}$ & $10.48 \pm 5.20$ & $9.88 \pm 4.54$ \\
\hline${ }^{*} \mathrm{p}<0.05,{ }^{\dagger}$ Significant difference from $90^{\circ}$ shoulder flexion, ${ }^{*}$ Significant difference from $135^{\circ}$ shoulder flexion
\end{tabular}

to posterior deltoid muscle activity during shoulder ER at $45^{\circ}, 90^{\circ}$, and $135^{\circ}$ of shoulder flexion.

\section{SUBJECTS AND METHODS}

A total of 13 healthy males (mean age, $24.31 \pm 1.55$ years; mean weight, $68.38 \pm 7.26 \mathrm{~kg}$; mean height, $174.85 \pm$ $5.27 \mathrm{~cm}$ ) without neck or shoulder pain participated in this study. Subjects were excluded if they had a history of neurologic diseases or surgery of the neck or shoulder. Ethical approval was obtained from the Inje University Faculty of Health Science Human Ethics Committee, and all subjects signed an informed consent form prior to participation.

A surface EMG system (Delsys Inc., Boston, MA, USA) was used to acquire the EMG data of the infraspinatus and posterior deltoid muscles. The sampling rate was $2000 \mathrm{~Hz}$ with a bandwidth of 20 to $450 \mathrm{~Hz}$. The hair was shaved and the skin was cleansed with an alcohol swab for placement of the electrode to minimize skin impedance prior to electrode attachment. Electrodes were placed $4 \mathrm{~cm}$ below and parallel to the spine of the scapula on the lateral aspect over the infrascapular fossa and $2 \mathrm{~cm}$ below the lateral border of the spine of the scapula parallel to the muscle fibers on the dominant side to record the muscle activity of the infraspinatus and posterior deltoid of the dominant side, respectively ${ }^{11)}$. To normalize the muscle activity of the infraspinatus and posterior deltoid muscles, the maximum voluntary isometric contraction (MVIC) technique was performed as recommended by Kendall et al ${ }^{12}$. Raw data were converted into the root mean square (RMS) and then expressed as $\%$ MVIC.

All subjects performed shoulder ER in three arm positions in the sagittal plane $\left(45^{\circ}, 90^{\circ}\right.$, and $135^{\circ}$ of shoulder flexion). Prior to the experiment, all subjects were instructed to perform correct shoulder ER movement to prevent compensatory strategies such as forearm supination, and they practiced these movements until they were familiar with the correct method of performing shoulder ER. To perform shoulder ER, the subjects were asked to extend the elbow and flex the shoulder of the dominant side to the tar- get angle. An examiner confirmed the target angle using a goniometer. The subjects performed shoulder ER in the target arm position and maintained the end range of shoulder ER for $5 \mathrm{~s}$. The shoulder flexion angle was selected in a random order. The shoulder ER exercises were repeated three times in each arm position condition, and rest periods of 1 and 3 min were provided between trials and conditions, respectively.

The mean value of the \%MVIC of the middle $3 \mathrm{~s}$ in each trial was collected for data analysis, and the mean value of three test trials was used to compare the muscle activity of the infraspinatus and posterior deltoid muscles as well as the ratio of the infraspinatus to posterior deltoid muscle activity among the conditions.

To determine the main effects of arm position in the sagittal plane, one-way repeated-measures analysis of variance was used. Comparative analysis among the three conditions was performed using post hoc analysis with Bonferroni's correction. Statistical significance was set at $\mathrm{p}<0.05$, and data were analyzed using PASW Statistics Ver. 18.0 (SPSS, Inc., Chicago, IL, USA).

\section{RESULTS}

Table 1 shows the descriptive statistics of the EMG activity of the infraspinatus and posterior deltoid muscles. The EMG activity of the posterior deltoid muscle was significantly different among the conditions $(p=0.016)$. Post hoc analysis revealed that the posterior deltoid muscle activity was significantly decreased during shoulder ER at $45^{\circ}$ of shoulder flexion compared with $90^{\circ}$ and $135^{\circ}$ of shoulder flexion $(p<0.05)$. There was no significant difference in the infraspinatus muscle activity among the conditions ( $p$ $>0.05)$.

The ratio of the infraspinatus to posterior deltoid muscle activity was significantly different among the conditions ( $p$ $=0.029$ ) (Table 2). A greater ratio of infraspinatus to posterior deltoid muscle activity during shoulder ER was found at $45^{\circ}$ of shoulder flexion than at $90^{\circ}$ and $135^{\circ}$ of shoulder flexion $(\mathrm{p}<0.05)$. 


\section{DISCUSSION}

Selective strengthening of the infraspinatus muscle has been emphasized in rehabilitation of the shoulder joint ${ }^{8,9)}$. Previous studies have described various exercises that increase the activation of the infraspinatus muscle ${ }^{6,8,9)}$. However, the effects of arm position in the sagittal plane on the muscle activity of the infraspinatus and posterior deltoid muscles were not clearly demonstrated in these previous studies. The findings of the present study showed that $45^{\circ}$ of shoulder flexion reduced the contribution of the posterior deltoid muscle during shoulder ER exercises compared with $90^{\circ}$ and $135^{\circ}$ of shoulder flexion.

In the present study, the EMG activity of the posterior deltoid muscle was significantly lower during shoulder ER at $45^{\circ}$ of shoulder flexion that at $90^{\circ}$ and $135^{\circ}$ of shoulder flexion. Overactivation of the posterior deltoid muscle may lead to superior or anterior translation of the humeral head, which can induce shoulder pain ${ }^{7,8}$. Therefore, the contribution of the posterior deltoid muscle to shoulder ER must be monitored during shoulder ER exercises. Ackland and Pan$\mathrm{dy}^{10)}$ investigated changes in the moment-arm of the shoulder muscles at various shoulder flexion angles and reported that the posterior deltoid muscle acts primarily as a shoulder ER rotator during shoulder flexion. The anatomical role of the posterior deltoid muscle implies that an increased shoulder flexion angle leads to greater EMG activity of the posterior deltoid muscle, which may have influenced our findings.

The infraspinatus muscle activity, however, did not differ among the conditions in this study. This is in disagreement with the findings of $\mathrm{Ha}$ et al. ${ }^{9}$, who reported that an increased shoulder flexion angle may facilitate the EMG activity of the infraspinatus. However, shoulder ER was performed without an additional load in the present study, while Ha et al. ${ }^{9)}$ performed shoulder ER exercises under an additional load condition. We consider that these differences in the experimental conditions may have contributed to the lack of significant differences in the infraspinatus muscle activity among the conditions in the present study.

Despite the lack of significant changes in the EMG activity of the infraspinatus muscle, the ratio of the infraspinatus to posterior deltoid muscle activity was significantly greater at $45^{\circ}$ of shoulder flexion than at $90^{\circ}$ and $135^{\circ}$ of shoulder flexion during shoulder ER in this study. Anatomically, the posterior deltoid muscle contributes to shoulder ER because of its muscle fiber orientation, together with the infraspinatus muscle ${ }^{7}$.12). However, the infraspinatus muscle reportedly has a larger stabilizing role than torque-producing role during shoulder $\mathrm{ER}^{8)}$. It is reasonable that the ratio of the infraspinatus to posterior deltoid muscle activity is empha- sized in shoulder ER exercises. Nevertheless, few studies have evaluated the ratio of the infraspinatus to posterior deltoid activity ${ }^{8,13)}$. Therefore, our findings can provide clinicians with useful information when they want to facilitate infraspinatus muscle activity without excessive muscle activity of the posterior deltoid during shoulder ER exercise in the clinical setting. Based on the present findings, shoulder ER exercises at $45^{\circ}$ of shoulder flexion rather than $90^{\circ}$ or $135^{\circ}$ of shoulder flexion may be useful for reducing the contribution of the posterior deltoid.

This study has some limitations. First, only 13 individuals participated in the study; therefore, it is difficult to generalize our results. Second, our findings showed significant differences in the EMG activity of the posterior deltoid muscle among the conditions; however, the difference was small. It is considered that the lack of additional load during shoulder ER was responsible for these results. Future studies should examine whether an additional load changes the muscle activity of the infraspinatus and posterior deltoid during shoulder ER under various arm positions in the sagittal plane.

\section{REFERENCES}

1) Apreleva M, Hasselman CT, Debski RE, et al.: A dynamic analysis of glenohumeral motion after simulated capsulolabral injury. A cadaver model. J Bone Joint Surg Am, 1998, 80: 474-480. [Medline]

2) Ballantyne BT, O'Hare SJ, Paschall JL, et al.: Electromyographic activity of selected shoulder muscles in commonly used therapeutic exercises. Phys Ther, 1993, 73: 668-677, discussion 677-682. [Medline]

3) Sciascia A, Kuschinsky N, Nitz AJ, et al.: Electromyographical comparison of four common shoulder exercises in unstable and stable shoulders. Rehabil Res Pract, 2012, 2012: 783824. [Medline]

4) Wilk KE, Arrigo CA, Andrews JR: Current concepts: the stabilizing structures of the glenohumeral joint. J Orthop Sports Phys Ther, 1997, 25: 364-379. [Medline] [CrossRef]

5) Terry GC, Chopp TM: Functional anatomy of the shoulder. J Athl Train, 2000, 35: 248-255. [Medline]

6) Reinold MM, Wilk KE, Fleisig GS, et al.: Electromyographic analysis of the rotator cuff and deltoid musculature during common shoulder external rotation exercises. J Orthop Sports Phys Ther, 2004, 34: 385-394. [Medline] [CrossRef]

7) Sahrmann SA: Diagnosis and Treatment of Movement Impairment Syndrome. St. Louis: Mosby, 2002.

8) Bitter NL, Clisby EF, Jones MA, et al.: Relative contributions of infraspinatus and deltoid during external rotation in healthy shoulders. J Shoulder Elbow Surg, 2007, 16: 563-568. [Medline] [CrossRef]

9) Ha SM, Kwon OY, Cynn HS, et al.: Selective activation of the infraspinatus muscle. J Athl Train, 2013, 48: 346-352. [Medline] [CrossRef]

10) Ackland DC, Pandy MG: Moment arms of the shoulder muscles during axial rotation. J Orthop Res, 2011, 29: 658-667. [Medline] [CrossRef]

11) Criswell E: Introduction to Surface Electromyography (2nd ed). Sudbury: Jones and Bartlett Publishers, 2010.

12) Kendall FP, McCreary EK, Provance PG, et al.: Muscles: Testing and function with posture and pain (5th ed). Baltimore: Williams \& Wilkins, 2005.

13) Kim JW, Yoon JY, Kang MH, et al.: Selective activation of the infraspinatus during various shoulder external rotation exercises. J Phys Ther Sci, 2012, 24: 581-584. [CrossRef] 